\title{
Optimum Efficiency Analysis and Simulation for Separable Transformer of Contactless Excitation Energy Transfer
}

\author{
Jinfeng Liu ${ }^{1}$, Xudong Wang ${ }^{1}$ and Rui Gong ${ }^{2}$ \\ ${ }^{1}$ School of Electrical \& Electronic Engineering, Harbin University of Science \& \\ Technology, Harbin, China \\ ${ }^{2}$ State Grid Heilongjiang Electric Power Company Limited, China \\ ljf78118@163.com
}

\begin{abstract}
In order to solve the problem about the brush and slip ring in drive motor of renewable energy vehicle, high frequency power magnetic field produced by a noyel separable magnetic pot transformer could achieve contactless excitation energy transfer. For contactless energy transfer (CET) system, its research about energy and efficiency quality still remains a low level because application and research of CET are not integrated, especially how to improve transmission power and efficiency is still not enough. First of all in this paper, the topology of magnetic pot tcansformer is built to design resonant compensation circuit. Secondly, mutual inductance parameter is proposed by optimum efficiency analysis through calculation. Thirdly, circuit simulation model of Matlab and $3 D$ simulation model of Ansoft Maxwell which can complete finite element transient analysis are built to verify the accuracy of optim(Int efficiency analysis. Lastly, the experiment platform about CET in symchron@us generator prototype is performed. Although the output power had little increase, experiment and Matlab, Ansoft 3D simulation research proved that system efficiency had a quite increase based on optimum efficiency analysis.
\end{abstract}

Keywords: contactles energy transfer, magnetic pot transformer; optimum efficiency analysis; finite element transient simulation

\section{Introduction}

Contactless energy t ansfer technique is widely used in various fields such as electric vehicle, underwater equipment, portable device, etc. which has need of energy transmission. This teehnique can realize energy transfer based on electromagnetic coupling theory through the combination of electronic power converter and control technology. And this kind of method can conquer the defects such as sliding abrasion, touching-spark and carbon deposit in conventional excitation system.

To realize brushless excitation, synchronous machine always adopted alternating carrent (AC) exciter and rotary rectifier. This technology greatly complicated the machine structure and control process. So some papers also report research on brushless excitation. Nonaka S. [1] proposed a scheme with no brush and exciter. Its stator winding was two suite of parallel three phase winding and one suite of direct current (DC) winding. This DC winding would generate static DC magnetic field in air gap. Rotor winding could make induced electromotive force (EMF) by cutting this magnetic field. Rotor winding was shortened by diode and then built rotating excitation field. Obviously, excitation current of machine was fluctuation and interrupt would even occur. Inoue K. [2] proposed fifth harmonics of magnetic field in air gap to excite. This method was inconvenient to adjust voltage because it needed to design suitable machine parameters and then assured the voltage remain stable when machine ran at constant revolutions per minute (rpm). 
Fukami T. [3] proposed an approximate method which placed one suite of three phase winding to motivate harmonics on stator. The winding was shortened by capacitor with $\mathrm{Y}$ connection. These methods have much in common and there were not only synchronous rotating magnetic field but also additive asynchronous rotating vice magnetic field. Although these schemes could realize brushless excitation by electromagnet induction, they weren't widely used in industry and science because of their complicated control for magnetic.

Therefore, new contactless energy coupling technology has been invented to improve these detects which based on new technology about induction energy transmission theory. The character by using induction technology is the relative sites of subsystem are stable, and it can realize closed coupled and high transmission efficiency [4-5]. As power electronics technology, high-frequency electronic technology and magnetic materials are advancing dramatically and demands of contactless power transfer of electrical equipments for many circumstances are increasing, this new energy transmission technology is gradually increasing [6-7]. The core device of this system to achieve contactless electrical energy transmission is rotary separable magnetic pot transformer, which ut lizes the benefit about transmission efficiency won't be influenced by rotate speed when primary or secondary winding of magnetic pot transformer keep rotating state. Figure 1 shows actual object for separable magnetic pot transformer/Figure 2 shows the diagram of the contactless excitation energy transfer system using electromagnetic coupling theory to realize energy transfer in synchronous motor.

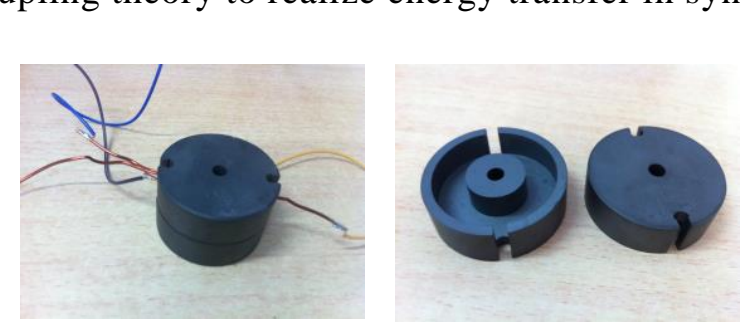

Figure 1Magnetic Pot Transformer Physical Figure

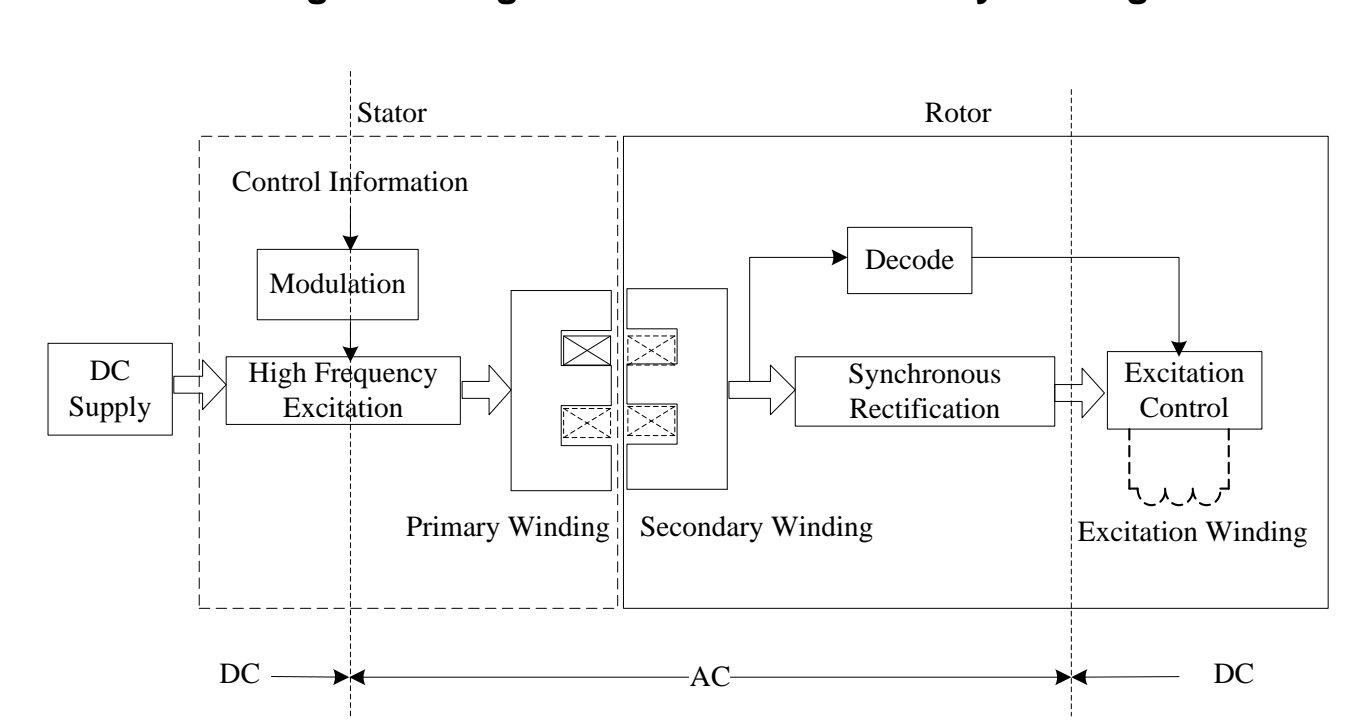

Figure 2. Contactless Excitation Energy Coupling System

Energy coupling diagram is composed of two parts when magnetic pot transformer is the cut-off point. On the left side of the dotted box is the synchronous motor stator, which provided DC power by the on-board battery, as the same time it provides high-frequency 
alternating current transformer to primary winding through the high frequency excitation inverter. Primary winding induces energy to secondary winding by electromagnetic coupled and then provide energy to the excitation winding of synchronous motor by synchronous rectification. Secondary winding can determine the increasing magnetic mode or weakening magnetic mode of the synchronous motor through decoding.

\section{Transformer Topology Model}

In the power conversion circuit, primary and secondary windings of the transformer model are used to describe the coupled relationship. This model is suitable for the condition of primary and secondary tight coupled model in the transformer, primary and secondary voltage meet the ratio of their turns, meanwhile the leakage inductance is usually negligible [8]. Mutual inductance model is another way to describe the coupled between primary and secondary windings of the circuit model. Induced voltage and coupled voltage can be fixed by mutual inductance, coupled voltage reflect the full impact of secondary to primary winding which do not need to separate the mutual inductance and leakage inductance, all above is the main advantage of this model analysis [9]. The essential difference between the contactless transformer and the traditional transformer is the coupled difference between primary and secondary coupled. To the traditional transformer, the coupled coefficient is usually between $0.95 \sim 0.98$, and close to 1 . Contactless transformer belongs to loosely coupled system, coupled coefficient is all below 0.9 , sometimes even less than 0.1 [10]. This transformer has the extensive leakage inductance and the core always works in the Ainear section of the magnetization curve. Considering the advantages of analysis the mutual inductance model and loosely coupled characteristic of contactless transformer, it's more applicable that use the mutual inductance model to represent the separable transformer equivalent circuit model. Figure 3 shows the mutual inductance mode circuit topology of contactless transformer. Where $\mathrm{U}_{1}$ is primary winding excitation ol age, $\mathrm{L}_{1}$ and $\mathrm{L}_{2}$ are primary winding inductance and secondary winding inductance respectively, $\mathrm{M}$ is the mutual inductance of the separable transformer, $\mathrm{R}_{1}$ and $\mathrm{R}_{2}$ are primary winding and secondary winding resistance respectively, $R_{o}$ is the load resistance. In order to improve system performance and the ability to power trânsmission, the resonant compensation technology is used in primary winding and secondary winding respectively.

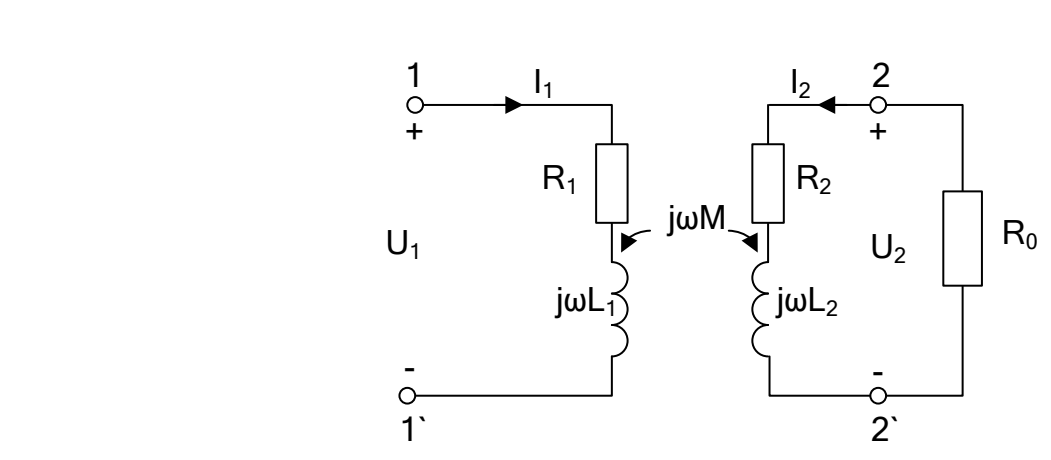

Figure 3. Mutual Inductance Model of Separable Transformer

\section{Characteristic Analysis of Separable Transformer}

\subsection{Analysis of Primary and Secondary Winding Equivalent Circuit Impedance}

We could get primary and secondary winding current from equation (1) and (2) when input voltage $\mathrm{U}_{1}$ is sine according Figure 4. 


$$
\begin{gathered}
I_{1}=\frac{U_{1}}{Z_{11}+(\omega M)^{2} Y_{22}} \\
I_{2}=\frac{-j \omega M Y_{11} U_{1}}{Z_{22}+(\omega M)^{2} Y_{11}}
\end{gathered}
$$

Where, $Z_{11}=R_{1}+j \omega L_{1}$ is primary impedance, $Y_{11}=1 / Z_{11}$, and $Z_{22}=R_{2}+j \omega L_{2}+R_{0}$ is secondary impedance, $\mathrm{Y}_{22}=1 / \mathrm{Z}_{22}$.

If $\mathrm{Z}_{\mathrm{r}}=(\omega \mathrm{M})^{2} \mathrm{Y}_{22}$, primary input impedance is $\mathrm{Z}_{11}+\mathrm{Z}_{\mathrm{r}}$ according equation (1). The influence of secondary system to primary system is reflected by the $Z_{r}$. In other words, $Z_{r}$ represents the influence of secondary circuit load on primary circuit current in transformer and becomes the equivalent impedance in primary circuit. There is contrary quality between $\mathrm{Z}_{\mathrm{r}}$ and $\mathrm{Z}_{22}$. If $\mathrm{Z}_{22}$ is inductive, $\mathrm{Z}_{\mathrm{r}}$ is capactive. While $\mathrm{Z}_{22}$ is capactive, $\mathrm{Z}_{\mathrm{r}}$ is inductive. We can ignore winding resistance in order to simplify impedance analysis because load resistance should be much higher than winding resistance. If $Z_{r}=R+j X$, where $R_{r}$ and $X_{r}$ represent reflected resistance and reflected reactance respectively, we could get:

$$
\begin{gathered}
R_{r}=\frac{\omega^{2} M^{2} R_{o}}{\omega^{2} L_{2}^{2}+R_{o}^{2}} \\
X_{r}=-\frac{\omega^{3} M^{2} L_{2}}{\omega^{2} L_{2}^{2}+R_{o}^{2}}
\end{gathered}
$$

So primary impedance reflected by seconary circuit if capacitive impedance when secondary circuit has no compensation.

\subsection{Capacitance Compensation}

The primary and secondary circyit reactance increase several times over with the decline of coupled coefficient and increase of operating frequency of the separable transformer [11]. In order to achieve a certain power output, the power supply voltage must be raised and the uilization rate of the system will be reduced greatly. In order to improve the performance, reactive power of primary and secondary circuits must be compensate. Through primary compensation can improve primary winding at the input power factor, meanwhile it could improve the quality of power supply [12]. Under the same condition of primary input voltage, through secondary compensation, it can improve the output power and the transmission efficiency of the system.

Primary winding of the contactless transformer always connects with the switch of converter, and then primary voltage will be loaded on the switch directly, so primary winding currentall thow through the switch and lead to the high rating value of voltage and current Through the resonance of the compensation capacitor $\mathrm{C}_{1}$ and primary winding inductance $\mathrm{L}_{1}$, it will compensate the voltage on primary winding, that is to say the voltage on the compensation capacitor $\mathrm{C}_{1}$ will offset the voltage on primary winding $\mathrm{L}_{1}$ p rtty or completely and reduce the voltage stress of switching tube at the same time. Aceording to the conditions of primary series resonance we can get series compensation capacitor $\mathrm{C}_{1}$ is:

$$
C_{1}=\frac{1}{\omega^{2} L_{1}}
$$

The contactless magnetic pot transformer secondary windings are connected to the load directly, the output voltage and current of the converter will change with the change of load, so secondary system must be compensated. At the resonance of the compensation capacitor $\mathrm{C}_{2}$ and secondary inductance $\mathrm{L}_{2}$, we can take secondary winding as a resistance which the output voltage doesn't related to the load. So secondary induction voltage can 
be regarded as constant voltage source. According to the resonant conditions of secondary series resonance we can get series resonant compensation capacitance $C_{2}$ is:

$$
C_{2}=\frac{1}{\omega^{2} L_{2}}
$$

When the series resonant compensation is used to secondary winding the reflection impedance is:

$$
Z_{r}=\frac{\omega^{4} C_{2}^{2} M^{2} R_{o}-j \omega^{3} C_{2} M^{2}\left(1-\omega^{2} C_{2} L_{2}\right)}{\left(1-\omega^{2} C_{2} L_{2}\right)^{2}+\omega^{2} C_{2}^{2} R_{o}^{2}}
$$

When secondary compensation circuit is in resonant state:

$$
\omega=\frac{1}{\sqrt{L_{2} C_{2}}}
$$

The reflection impedance is simplified :

$$
Z_{r}=\frac{\omega^{2} M^{2}}{R_{o}}
$$

The reflection impedance of secondary winding is resistance when the series resonant compensation is used to secondary winding. The coupling coefficient of transformer could be got from equation (10).

$$
K=\frac{M}{\sqrt{L_{1} L_{2}}}
$$

Magnetic pot transformer and winding size are designe Cas follows: outside diameter $10 \mathrm{~mm} \times$ inside diameter $4 \mathrm{~mm} \times$ height $8 \mathrm{~mm}$ on core, outside diameter $9 \mathrm{~mm} \times$ inside diameter $4 \mathrm{~mm} \times$ height $8 \mathrm{~mm}$ on winding, primary number of turns and secondary number of turns are 24. It will get the parameters as follows. $\mathrm{L}_{1}=2.76 \mu \mathrm{H}, \mathrm{L}_{2}=2.63 \mu \mathrm{H}, \mathrm{R}_{1}=\mathrm{R}_{2}=$ $0.26 \Omega$, Series compensation capacitor $\mathrm{C}_{1}=\mathrm{C}_{2}=3.67 \mu \mathrm{F}$. Then we could get resonant frequency is $50 \mathrm{kHz}$. Figure 4 shows the outpug vaveform before compensation and after compensation respectively. Current of primary winding presents approximate linearity and the core worked in linear area of magnetized curve with no compensation because transformer has larger Teakage inductance. While the current of primary winding appears approximate sine with series-series compensation. It could prove series compensation capacitance would generate resonance with primary and secondary inductance, and then effectively weaken the influence of leakage inductance. The voltage amplitude of secondary winding and transport power have raised.

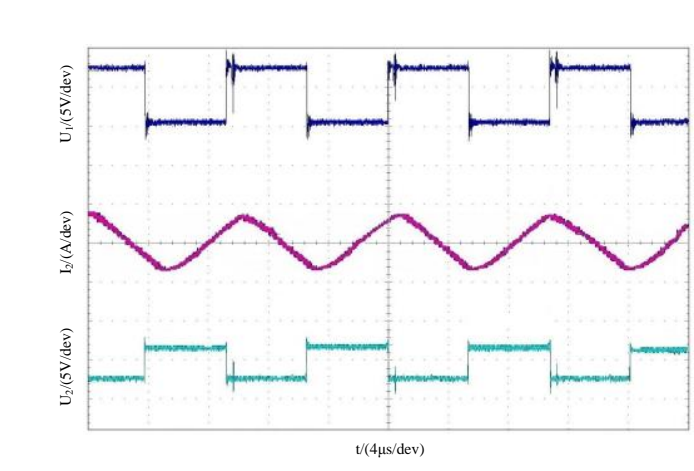

(a) waveform with no compensation

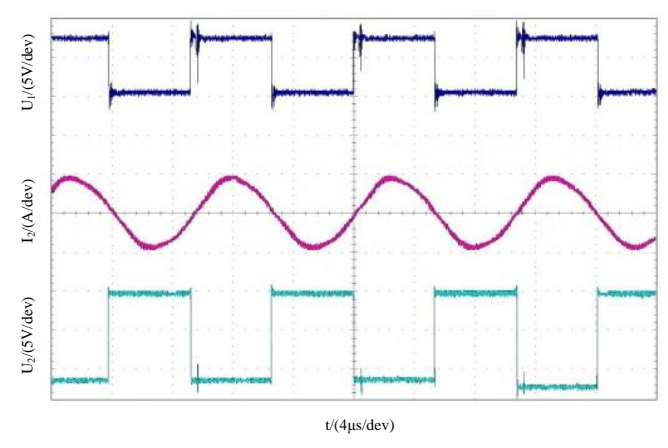

(b) waveform with compensation

Figure 4. Input and Output Waveform with Series \& Series Resonant Compensation or Not 


\section{Parameters Optimized Analysis Based on Optimum Efficiency Analysis}

Electromagnet induction coupling structure is the core of contactless energy coupling system and its principle is in accordance with common transformer. Somewhat differently, common transformer is tight coupling model and its magnetic flux is distributed mainly over iron core while flux leakage is little because of the high permeability and low reluctance of iron core, so it has tight coupling extent. But the magnetic path of CET belongs to loosely coupling model. Magnetic flux will flow not only in the coil but also in the air magnetic path because the air gap between primary and secondary coil is big, so CET's flux leakage is much and coupling extent is low. The structure of CET has seriously affected power transmission capacity of system and reduced power transmission efficiency.

\subsection{Propose Optimum Efficiency Analysis}

In order to realize optimum design of system in its totality we should consider not only how to improve efficiency of system as far as possible but also various indicators such as cost, volume, reliability, withstand voltage of implement and so on based on maximum power transmission in the design process of modern electric system. So the assessment function of system is no longer efficiency which is single objective function but multiple objective function which have allowed for above variables. Only realized these objective function can come to the conclusion that the system is optimum. In order to combine with variables of system we need a new assessment indicator because previous efficiency couldn't satisfy requirement[13].

It's not the most ideal result of designen that optimized mutual inductance by taking the CET 's maximum transmission power as target in design process of real system. Then a novel synthetical assessment indicator, maximum load ratio \& efficiency product which applied to CET system was proposed that overoame disadvantage of maximum power or efficiency as optimized factor. It would optimize and analyze mutual inductance coupling parameter of system, thereby realizing overall situation optimum.

We can take output power of CET 's system as design target. In order to analyze easily and eliminate system output power effect of input voltage, output power must be normalized treat ment. Suppose $\varphi$ as the ratio of actual output power to maximum output power, that is, $\varphi$ is load rato of system. We take $\varphi$ as system target and load ratio \& efficiency product will be derived according to the definition:

$$
\xi=\eta \times \varphi
$$

\subsection{Optimized Mutual Inductance Coupling Parameter for Series\&Series Type Circuit}

System elficiency is just only $50 \%$ in series\&series harmonic compensation circuit underthe maximum output power. System could realize maximum output power based on optimized mutual inductance coupling parameter at the expense of dramatic decline of efficiency. In order to improve efficiency and guarantee certain transmission power, designer must increase input voltage, raise system cost and decrease reliability. While system efficiency should be improved as far as possible, cost and volume should be reduced and then reliability would be increased in the design process of real system based on certain transmission power. By means of analysis, expression of transmission efficiency about CET system for series-series type is:

$$
\eta_{s s}=\frac{P_{s s-o u t}}{P_{s s-\text { in }}}=\frac{\omega^{2} M^{2}}{\omega^{2} M^{2}+R_{o} R_{1}}
$$

When secondary winding resistance is ignored output power is: 


$$
P_{s s-o u t}=\frac{\omega^{2} M^{2} U_{1}^{2} R_{o}}{\left(\omega^{2} M^{2}+R_{o} R_{1}\right)^{2}}
$$

In order to derive the relationship between output power and mutual inductance, we could make $d P_{s s-o u} / d M=0$, So we would get optimized mutual inductance under the maximum transmission power:

$$
M_{s s-o p t}=\frac{\sqrt{R_{o} R_{1}}}{\omega}
$$

According to equation (15) we could know that optimum efficiency analysis would be got while system couldn't obtain optimum efficiency in order to realize maximum transmission power. We could get the maximum output power according to equation (13) and (14).

$$
P_{s S-\max }=\frac{U_{1}^{2}}{4 R_{1}}
$$

Load ratio of CET system for SS type on the basis of its definition is:

$$
\varphi_{s s}=\frac{4 \omega^{2} M^{2} R_{o} R_{1}}{\left(\omega^{2} M^{2}+R_{o} \mathrm{R}_{1}\right)^{2}}
$$

Then load ratio \& efficiency product is:

$$
\xi_{s s}=\eta_{s s} \times \varphi_{s s}=\frac{\left.4 \omega^{4} M^{4} R_{o} R_{1}\right)}{\left(\omega^{2} M^{2}+R_{o} R_{1}\right)^{3}}
$$

We could make:

$$
\frac{d \xi_{s s}}{d M}=\frac{d\left(m_{s s} \times \varphi_{s s}\right)}{S d M}=0
$$

When:

$$
M_{s s-\xi}=\frac{\sqrt{2 R R_{1}}}{\omega}
$$

Load ratio \& efficienc product woyld be maximum. Now output power and efficiency are:

$$
\begin{aligned}
& P_{s s-\xi}=\frac{2 U_{1}^{2}}{9 R_{1}} \\
& \eta_{s s-\xi}=\frac{2}{3}
\end{aligned}
$$

Table 1 shows the gontrast of output power and efficiency before and after the new indicator adopted

Table 1. Contrast of Output Power Units for Magnetic Properties

\begin{tabular}{|c|c|c|c|c|}
\hline & $P_{\mathrm{o}} / \mathrm{W}$ & $\eta / \%$ & $M / \mu H$ & $K$ \\
\hline Before $\xi$ adopted & $\mathrm{U}_{1}^{2} / 4 \mathrm{R}_{1}$ & 50 & 1.62 & 0.6 \\
\hline After $\xi$ adopted & $2 \mathrm{U}_{1}^{2} / 9 \mathrm{R}_{1}$ & 66.7 & 2.29 & 0.918 \\
\hline Enhancement & $-11.1 \%$ & $33.3 \%$ & $41.4 \%$ & $53 \%$ \\
\hline
\end{tabular}

From this table we could know CET system realized efficiency improvement of $33.3 \%$ at the cost of output power decrease of $11.1 \%$ under maximum load ratio \& efficiency product indicator. Meantime, we can get the mutual inductance $M$ and coupling coefficient $\mathrm{K}$ according to aforementioned transformer parameters. And the mutual inductance and coupling coefficient all obviously improved at maximum load ratio \& efficiency product. 


\section{Experiment and Simulation}

In order to verify accuracy of optimum efficiency analysis, the transformer structure and CET system must be carried out simulation and experiment analysis. We could make mutual inductance reach the requirement of maximum output power and optimum efficiency analysis by adjusting air gap of transformer to control coupling coefficient.

\subsection{Maximum Transmission Ability Research Based on Optimum efficiency analysis}

Figure 5 shows simulation model which is built on the basis of work condition. Mutual inductance of separable transformer would be assured based on maximum transmission power and optimum efficiency analysis respectively and then synthetical transmission performance of system would be analyzed.I

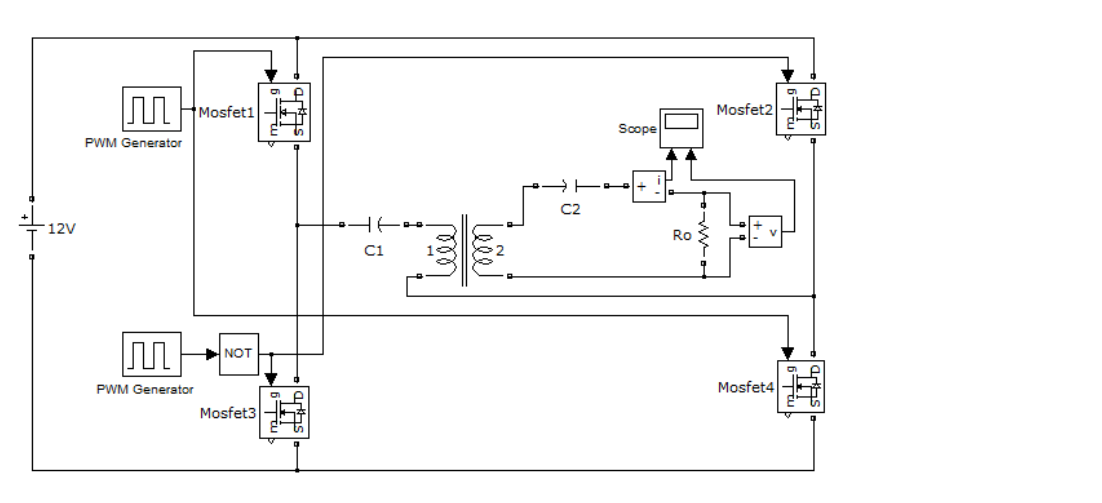

Figure 5. Simulation Model of CET System

We could put parameters which satisfed maximum transmission power and harmonic status into simulation mode1 Figure 6 shows the simulation waveform. $U_{o}$ is load voltage. $I_{o}$ is load current. $L_{i}$ and $I_{i}$ are input voltage and current respectively.
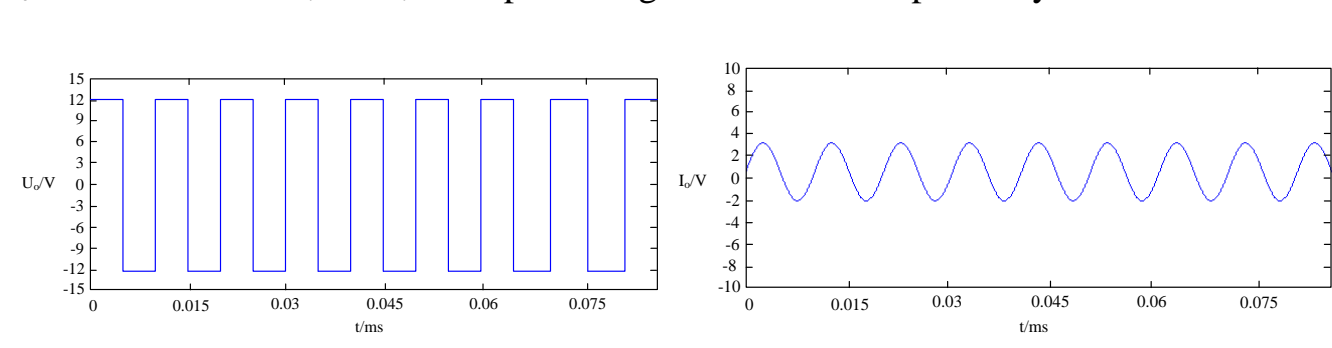

Figure 6. Output Waveform in Maximum Output Power

The phase of load current and voltage is accordance under ideal circumstance from waveform. Then the efficiency of system is :

$$
\eta_{p \max }=\frac{P_{o}}{P_{i}}=\frac{U_{o} I_{o}}{U_{i} I_{i}}=\frac{12 \times 3.5}{12 \times 7.3}=47.9 \%
$$

The transmission efficiency is more low in the mode of maximum output power. Optimum efficiency analysis indicator of transmission ability must be considered in order to obtain overall situation optimum. Mutual inductance coupling parameter of contactless transformer could be assured by equation (20), and then altered the transformer parameter. Figure 7 shows the simulation waveform in optimum efficiency analysis. 

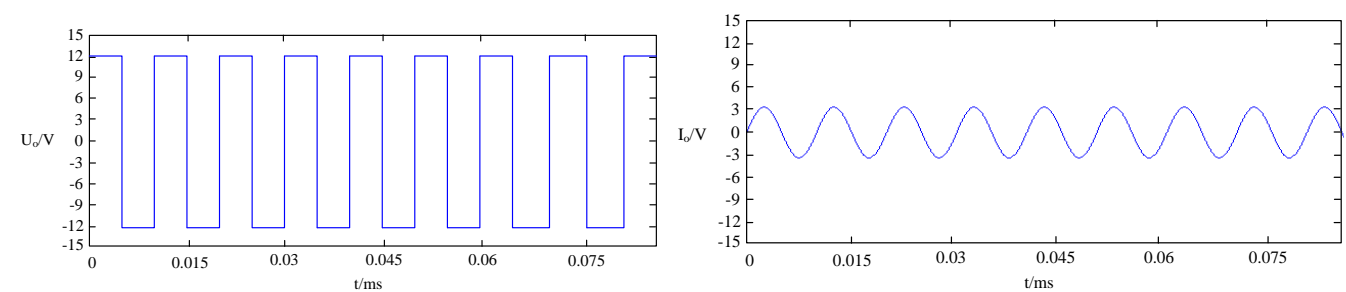

Figure 7. Output Waveform in Optimum Efficiency Analysis

The waveform sequence of Figure 7 and Figure 8 is accordance, and the phase of output voltage and current of secondary coil don't shift. So the efficiency of system is:

$$
\eta_{\xi \max }=\frac{P_{o}}{P_{i}}=\frac{U_{o} I_{O}}{U_{i} I_{i}}=\frac{12 \times 3.4}{12 \times 5.2}=65.4 \%
$$

Primary current decreased and transmission efficiency improved even though transmission power has been slightly reduced. These are accordance with former theory analysis. It's just because obvious decrease of primary current could reduce not only switch loss of former MOSFET but also heat loss of harmonic circuit. So the transmission quality of system is increased diamatically and parameters are overall optimized.

\subsection{Ansoft Simulation Research}

3D simulation model of separable transfformer through Ansoft Maxwell software based on the edge finite element according to design requirement of CET can be built and simulate in maximum output power and optimúm elficiency analysis, that's to say, we could contrast and analysis mutua inductance of this two kinds of indicator[14]. Figure 8 is Ansoft simulation model of separable trânsformer.

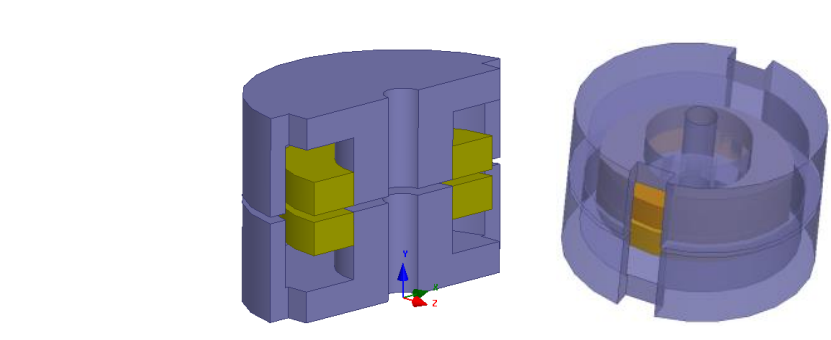

Figure 8. Separable Transformer Simulation Model

The frequency of input square wave voltage to primary winding is $100 \mathrm{kHz}$ and amplitude is $\pm 12 \mathrm{~V}$. Secondary winding of transformer and rotor of synchronous machine connect with same axis. The turns ratio is $1: 1$ and load resistance is $1 \Omega$. Figure 9 and Figu 10 are magnetic density distribution in different indicators and different moments. We-could find out clearly from Figure 9 and Figure 10 that the magnetic density of transformer in optimum efficiency analysis is higher than in maximum output power. 


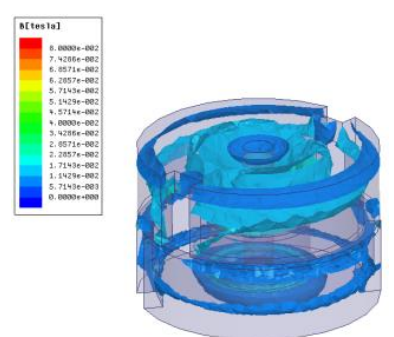

(a) $2 \mathrm{~ms}$

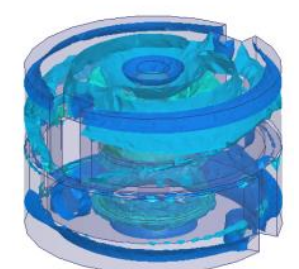

(b) $4 \mathrm{~ms}$

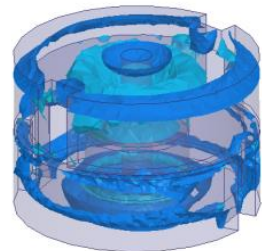

(c) $6 \mathrm{~ms}$

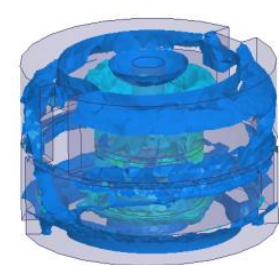

(d) $8 \mathrm{~ms}$

\section{Figure 9. Magnetic Flux Density in Maximum Output Power}

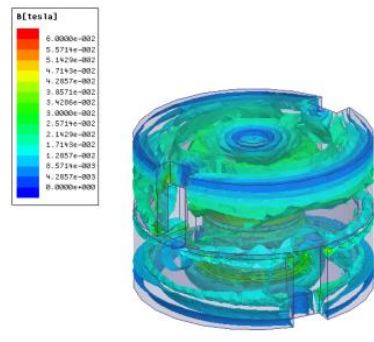

(a) $2 \mathrm{~ms}$

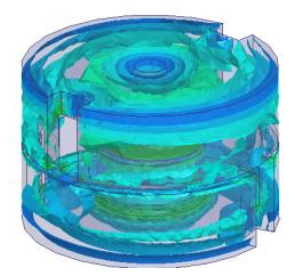

(b) $4 \mathrm{~ms}$

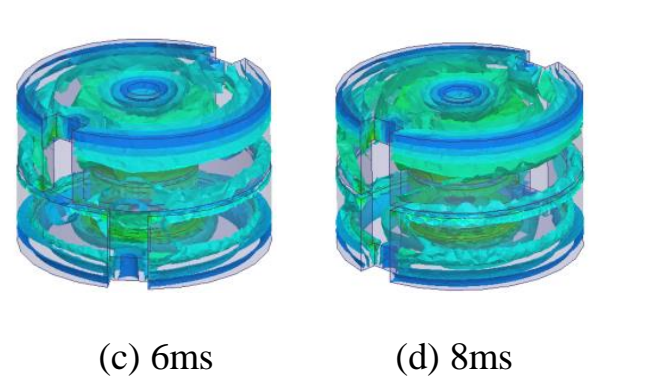

Figure 10. Magnetic Flux Density in Optimum Efficiency Analysis

\subsection{Experiment Research}

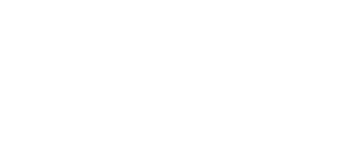

Contactless energy transmission system was built in laboratory under the control of LM5035B in order to verify validity of optimum efficiency analysis. Figure 11 is CET test prototype realized by separable transtormer. LM5035B could provide $100 \mathrm{kHz}$ and $\pm 12 \mathrm{~V}$ square wave for separable transformer in inverter circuit, then transformer transports it to reetifier unit which rotates with rotor of synchronous machine. The spacing between primary and secondary winding, revolution per minute and source frequency are all adjustable.

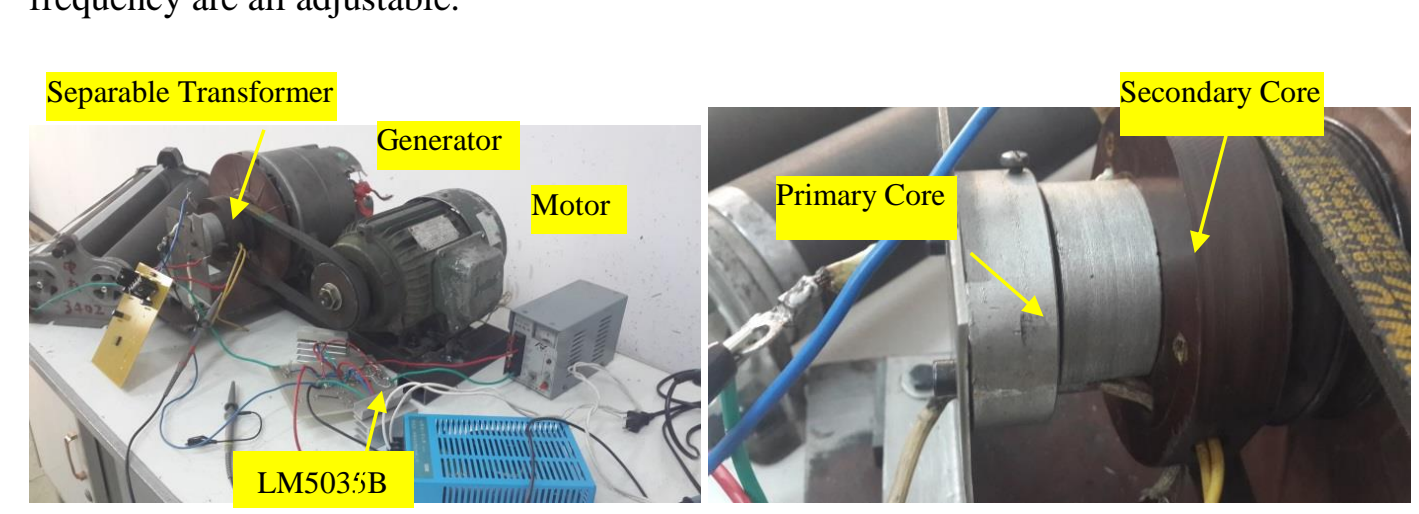

Figure 11. Excitation System Test Model Realized By Isolable Transformer

LM5035B could provide $100 \mathrm{kHz}$ and $\pm 12 \mathrm{~V}$ square wave for separable transformer in inverter circuit, then transformer transports it to rectifier unit which rotates with rotor of synchronous machine. The space between primary and secondary winding, revolution per minute and source frequency are all adjustable. According to the result of experiment, the efficiency can improve 30\% when optimum efficiency analysis was adopted and it's identical to the aforementioned analysis. 


\section{Conclusions}

Performance analysis was more complex to contactless energy coupling system which had series \& series harmonic compensation. So this paper proposed optimum efficiency analysis indicator which got from maximum load ratio \& efficiency product, realize energy transmission with high efficiency and power, reduce the investment cost, improve security of system. Then the transmission performance of CET system achieved optimum operating point.

\section{Acknowledgements}

This project is supported by the project "New method of contactless rotor excitation in synchronous machine", founded by the National Natural Science Foundation of China (No. 51177031).

\section{References}

[1] S. Nonaka and K. Kesamaru, "Analysis of brushless four-pole three-phase synchronøus generator without exciter by the finite element methed" , IEEE transactions on Industry Applications, vol. 3, no. 30, (2000).

[2] K. Inoue and H. Yamashita, "A brushless self-exciting three hase synchronous generator utilizing the 5th-space harmonic component of magneto motive force through armature currents", IEEE Transaction on Energy Conversion, vol. 3, no. 7, (2002).

[3] T. Fukami, T. Kondo and T. Miyamoto, "Analysis of a self-regulated, self-excited, brushless threephase synchronous generator which includes the effect of core losses", Electric Engineering in Japan, vol. 6, no. 131, (2000).

[4] A. Ikuo, "Design theory of Wireless Power Systen Based on Magnetically Coupled Resonators", IEEE International Conference on wireless Information Technology and System, Honolulu, United States, (2010).

[5] F. Mastri, A. Costanzo and M. Dionigi "Harmonic Balance Design of Wireless Resonant-type power transfer links", International Microwave Workshop Series on Innovative Wireless Power Transmission: Technologies, Systems, and Applications, Kyoto, Japan, (2012).

[6] C.-J. Chen, T.-H. Chu and C.-L. Lin, "A Study of Loosely Coils for wireless power transfer", IEEE Transactions on Circuits and System, vol.8 no. 57, (2010).

[7] K. Fotopoulou and W. Fyynn Brian, "Wireless power transfer in loosely coupled links:Coil misalignment model", IEEE Transactions on Magnetics, vol. 5, no. 47, (2011).

[8] R. M. Miskiewicz "Noncontact ower interface for plug-in electric vehicles in V2G systems", Bulletin of the Polish Academy of Sciences. Technical Sciences, vol. 4, no. 59, (2011).

[9] C.J. Chen, T.H. Chu, CL. Lin and Z.C. Jou, "A Study of Loosely Coils for wireless power transfer", IEEE Transactions on Cirruits System, vol. 7, no. 57, (2010).

[10] K. Fotopoulou and W Flynn Brian, "Wireless power transfer in loosely coupled links:Coil misalignment model", IEEE Transact ons on Magnetics, vol. 2, no. 47, (2011).

[11] H. Belloumi and F Kourda, "Self-oscillating half bridge series resonant converter at high efficiency", IEEE Mediteranean Electrotechnical Conference, Yasmine Hammamet, (2012).

[12] X. Zhang, Q.X. Yang and H.Y. Chen, "Modeling and Design and Experimental Verification of Contactless Power Transmission Systems via Electromagnetic Resonant Coupling”, Proceedings of the CSEE, vol. 21, no. 32, (2012).

[13] Y. Sun, C.Y. Xia and X. Dai, "Efficiency Analysis and Parameter Optimization of CPT System", Journal of Southwest Jiaotong University, vol. 6, no. 45, (2010).

. Wang, C. Pan and S. Zhou, "Transient magnetic-circuit coupled model of transformer based on edge inite element method", Transactions of China Electrotechnical Society, vol. 9, no. 27, (2012). 


\section{Authors}
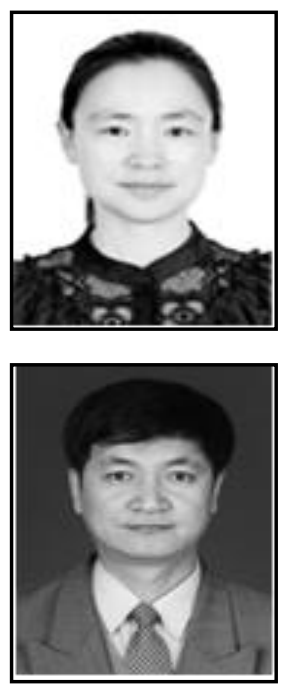

Jinfeng Liu, She received her Ph.D. degree in Electrical Engineering from Harbin University of Science \& Technology, China in 2011. Currently, She works as a teacher for Electronic Information and Electrical Engineering. Her research interests include machine control, magnetic field simulation, and EMC.

Xudong Wang, he received his Ph.D. degree in Electrical Engineering from Harbin Institute of Technology, China in 1981. Currently, He works for Automotive Electronics Engineering Center. His research interests include machine control, power electronic technology, and synchronous rectifier. 